\title{
LIMITTING CAPACITY OF PILED RAFT
}

\author{
V.BALAKUMAR \\ Senior consultant, Simplex Infrastructures Limited, Chennai, Tamil Nadu, India, \\ vb_kumar2002@yahoo.com \\ ERWIN OH, MARK BOLTON \& A.S.BALASUBRAMANIAM \\ Lecturer \& Professor of Civil Engineering GriffithUniversity Gold Coast Campus, \\ Brisbane, Australia, bala.balasubramaniam@griffith.edu.au
}

\begin{abstract}
The piled raft foundation is based on a skillful geotechnical concept wherein the pile group does not have any accountability for the safety and stability of the structure but performs the role of settlement reducer. In the design of piled raft, the capacity of the overall foundation system gains more importance than the capacity of individual constituting elements. Hence it becomes necessary to establish the limiting capacity of the piled raft so that the factor of safety for the overall system stability requirements can be assessed. The paper presents the details of the work done to establish a procedure to fix the limiting capacity of the piled raft based small scale $1 \mathrm{~g}$ model tests and an independent numerical study.
\end{abstract}

\section{INTRODUCTION}

The combined piled raft foundation system is the result of a skillful geotechnical concept developed by researchers to support structures sensitive for settlement. Piled raft foundation system has become an alternative for deep piles under certain favorable ground conditions, namely where the top soil has adequate bearing capacity and it will not undergo any settlement due to swelling or shrinkage. The concept of piled raft foundation system recognizes the fact that any structure has a certain amount of permissible settlement and the economy of the foundation design depends upon reducing the settlement to the permissible level rather than eliminating it in total. The combined piled raft foundation system takes advantage of the increased strength and stiffness caused by the enhancement of the confining stress due to the transfer of the applied load from the raft. The development of better under standing of the load transfer mechanism and the load sharing behavior of piled raft being so complex, and challenging that most of the researchers have been adopting analytical and numerical modeling, (Clancy, [1]; Poulos, [2]; Prokoso and Kulhawy [3] to study the behavior of the piled raft. Further the present developments in the computational and software facilities have made the analytical and numerical modeling relatively easier. But it is also to be borne in mind that certain amount of dilution in the rigorousness of the analyses is needed to make the problem computationally economical. However, many aspects on the behavior of piled raft have been brought out through small scale model studies, Balakumar, [4], Horikoshi [5]. Sustained research supported by the development of sophisticated computational facilities and FEA codes have improved the interaction process among the various methods of study, leading to the present state of understanding on the behavior of piled raft. As a result of such studies, large number of structures have been successfully supported on piled raft all over the world and have been reported Poulos[6], Yamashita etal [7] . Some of these structures have been instrumented. In many cases the results of such observational studies have been used to improve the design process for subsequent works. 


\section{OBJECTIVE AND SCOPE OF PRESENT STUDY}

The economics of the piled raft foundation system is governed by the pile group design. Number of trials is required in the initial stages of the piled raft design to decide the optimum number, length and the layout of piles before the final design. Apart from the numerical requirements of the constitutive elements of this system, a new requirement namely, the limiting capacity of the piled raft system has been identified, as it is not the pile capacity or the raft capacity are alone important, but the combined capacity of the pile group raft system is more important for the design. Even though the existing procedures fulfil all serviceability requirements, there is a requirement of determining the ultimate limit state of the piled raft so as to establish adequate factor of safety against failure that will ensure stability. This factor is often ignored as in majority of the cases the serviceability limit state of the superstructure becomes the deciding factor. The problem of bearing capacity of the piled raft is rather complicated and there is no unique mechanism that governs the failure of such complex piled raft and soil system. Even the numerical studies with the most advanced constitutive laws do not lead to any definite results. As such a simpler method of the estimation of the ultimate bearing capacity of the piled raft may be more useful.

\section{THE STUDY}

The present study is based on the results obtained from a series of $1 \mathrm{~g}$ model tests conducted on the square shaped piled raft, placed on a sand bed. Although extensive parametric studies were carried out, for the present the results of tests conducted on medium dense sand alone is taken. The details of the test set up and the procedure adopted for testing are all presented in our earlier publications. The results presented and discussed in the subsequent portions are related to the square piled raft with a pile raft area ratio (Ratio of the total cross sectional area of piles provided to the raft area expressed as a percentage) as $4.9 \%$.

During the same period extensive parametric studies were carried out on square shaped piled raft adopting PLAXIS -2D software by the geotechnical research team in Griffith University Gold Coast campus. Incidentally the Gold Coast area has a number of tall structures supported on piled raft but it appears none of the piled raft had been instrumented and monitored to study their response. The general soil profiles obtained from various sites were compared for the analyses to model the subsoil profile. The elastic modulus of the various strata was taken from the N-Values using standard correlations. The choice of elements and the meshing procedure were as per the PLAXIS manual. The details of the soil profile and models used are presented elaborately by $\mathrm{Oh}$ etal.[8]

\section{RESULTS ANALYSES AND DISCUSSIONS.}

This section explains the results obtained from the two independent studies and then the results are compared and discussed. In comparing the results of small scale model study and the two dimensional numerical analyses with Plaxis - 2D, the general trends are compared as the load level and the software used are different. Since both the studies had shown identical trends in the behavior, and it has been established that the two dimensional analyses is capable of producing results with a reasonable agreement with the $1 \mathrm{~g}$ model tests, the comparison is taken as justifiable.

\section{RESULTS}


The load settlement response of square shaped un-piled and piled raft is characterized and presented in Figure 1.

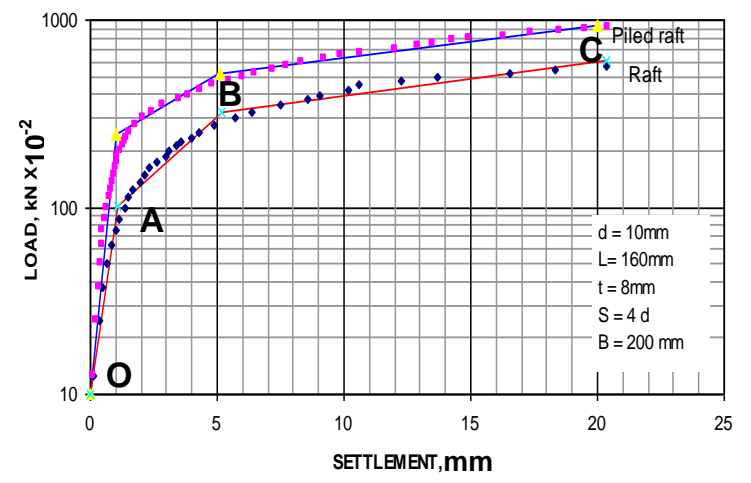

Figure 1. Characterised load-settlement response of plain raft \& piled raft in medium dense sand

Since the present study aims at defining the limiting load and the corresponding settlement level the load sharing response of the pile group of piled raft needs to be read in conjunction with the characterised load settlement response. Figure 2 presents the load sharing response of piled raft as a plot of load sharing ratio versus settlement.

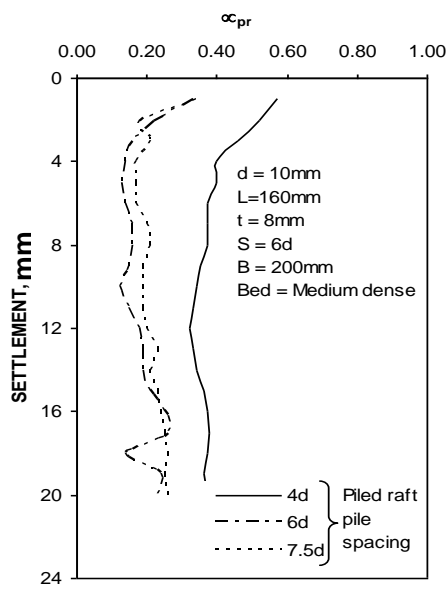

Figure 3. Variation in $\alpha_{\mathrm{pr}}$ with settlement for various spacing for $8 \mathrm{~mm}$ raft

The load sharing ratio is defined as,

$\alpha_{p r}=Q_{p} / Q_{p r}$ 
Where, $Q_{p}=Q_{p r}-Q_{r}$ Here $Q_{p r}$ is defined as the load taken by the piled raft at any given settlement, and $\mathrm{Q}_{\mathrm{r}}$ is defined as the load shared by the raft at the same settlement.

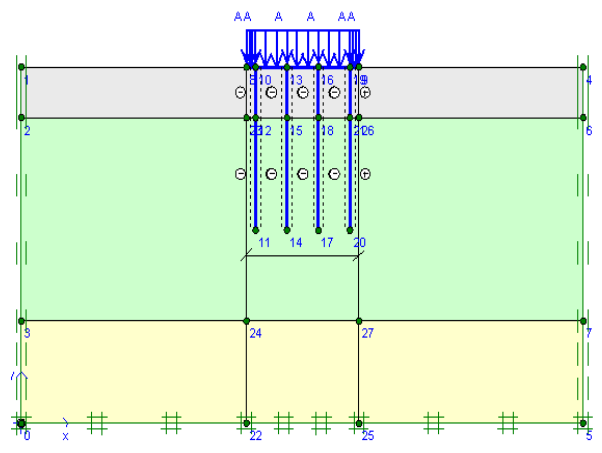

Figure 3. Plain Strain Model - PLAXIS

Figure 3 presents the Plaxis model used for the study along with the model used. In the study the raft size was kept as 11.5 meter square and the thickness was $800 \mathrm{~mm}$. 16 piles of $700 \mathrm{~mm}$ dia and $16 \mathrm{~m}$ long was considered. The pile raft area ratio was kept as $4.65 \%$ closely in agreement with the area ratio used in the $1 \mathrm{~g}$ model studies. The load settlement response is presented in Figure 4.

\section{ANALYSIS AND DISCUSSION}

The characterized load settlement response of the piled raft presented in the Figure 1 indicates that the load settlement response has three phases. The first phase OA presents a very stiff response and in this phase the rate of fall of stiffness is very low. This stage exists upto a settlement level of $1 \mathrm{~mm}$ to $1.5 \mathrm{~mm}$. Comparing this stage of behaviour with the load sharing response, it can be seen that till the settlement reaches $1 \mathrm{~mm}$ to $1.5 \mathrm{~mm}$, the load sharing ratio remains higher and the rate of fall is very low. This indicates that at this stage major part of the load is carried by the pile group. The stage $A B$ represents the elasto plastic stage in the characterised load settlement response. In this stage the rate of fall of stiffness increases but gradually, and this trend exists upto a settlement level of $6 \mathrm{~mm}$ to $8 \mathrm{~mm}$;in the case of load sharing response, the value of load sharing ratio reduces rapidly indicating that the pile group functions as a load bearing member but adds the stiffness required for the raft to take a higher load. Beyond this settlement level the load sharing ratio remains constant, corresponding to the phase $\mathrm{BC}$ which is plastic phase in the characterised response.. Hence it can be said that the piled raft system has two limiting capacities one relating to the elastic stage and the other corresponding to elasto plastic stage.

The load settlement response obtained from the study conducted in Griffith University considering the entire group as a single stubby pier of same length as the piles under consideration and the plan area as the equivalent area of the circular pier, the load settlement response has been obtained and presented in the Figure 4a.

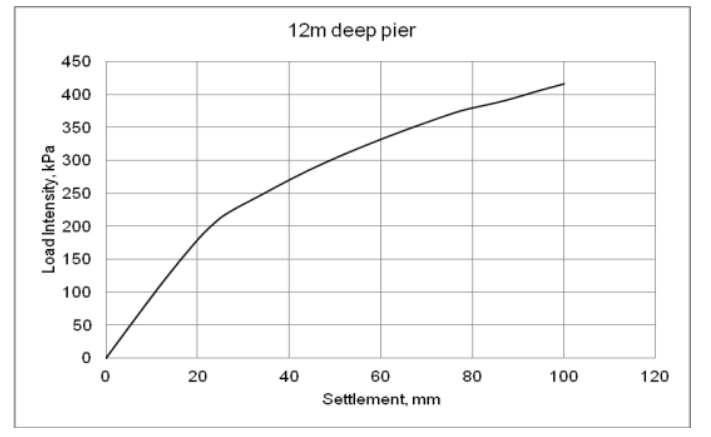

a

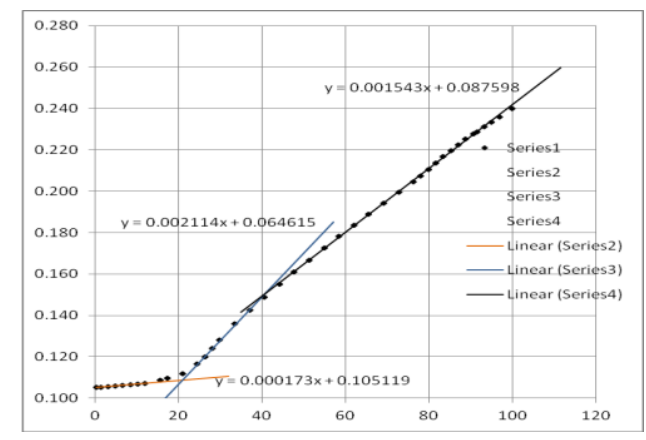

b

Figure 5(a) Load settlement response PLAXIS (b) Chin's graph (12m pier) 
The load settlement response of the pier raft system has been obtained considering the modulus of the pier as

Eeq $=$ Es $+($ Ep-Es $) \mathrm{At} / \mathrm{Ag}$

Where Eeq is the equivalent pier modulus, Es is the elastic modulus of the soil; Ep is the elastic modulus of the pile, the applicability of the equivalent pier approach to study the piled raft problem has been well established by Horikoshi [5]). The analyses was done by treating the problem as an axi-symmetric problem and the procedure becomes very simple. The first stage namely the elastic stage exists upto a settlement level of 12 to $13 \mathrm{~mm}$ which is $1.7 \%$ of the pile diameter. It is to be noted that while the model study results with the pile diameter is $8 \mathrm{~mm}$ are used to understand the behaviour in the field, the numerical study with the diameter of $700 \mathrm{~mm}$ (nearly 10 times more than the model diameter) which is more appropriate for the field condition and so the settlement is taken as function of the diameter. This would mean that a settlement level of $5 \%$ of the pile diameter the response tends to become elasto plastic and the pile group tends, to provide the raft additional stiffness to take more loads at any settlement level.

The behavior of the pile group of piled raft in sharing the load with reference to the settlement can be explained from the physical nature and behaviour of grains in contact. The mobilization of the stress inside a soil mass will increase with the strain as a function of an increasing number of effective soil grain contacts rather than of a general increase in the inter-granular stress on a fixed number of grain contacts. It can be visualized that when the compressive stress transferred due to the application of the load on the raft the load is transferred by internal columnar grain structures and as the applied stress increases more and more columns begin to support the load each having approximately same yield load. Any further increase in the load applied leads to either dilation or the loss of stiffness in the granular columns.

\section{DETERMINATION OF THE LIMITING LOAD}

If the pile group can be considered as a single stubby pier it is seen that in the initial stages of loading the pile group gains the additional frictional capacity due to the increase in the intergranular pressure and the system takes much higher load. When the strain level increases there is a certain amount of reduction in the inter-granular pressure and consequently the stiffness of the foundation system reduces. This situation occurs in the third stage in the characterization curve at a settlement level of $4 \%$ of the pile length in $1 \mathrm{~g}$ model and 4 to $6 \%$ of the pile diameter in the case of proto type. Considering the load settlement response as hyperbolic the settlement can be plotted 
against the inverse of the stiffness as proposed by Chin [9]. This has been presented in Figure 4b, and the limiting capacity of the pile group and the piled raft are marked in the same Figure. From the load settlement response, the load corresponding to the elastic and elasto plastic can be established as the limiting capacity of the piled raft corresponding to the elastic stage and elasto plastic stage and the corresponding settlement becomes critical settlement under the two stages.

\section{CONCLUSIONS}

The paper has established that the evaluation of the limiting capacity becomes an essential requirement in the design of the piled raft. It is seen that the load settlement response of the piled raft has got three stages and the load sharing response with settlement takes the same trend. Based on the above study there are two limiting capacities, one corresponding to elastic stage and the other corresponding to the elasto-plastic stage. The limiting capacity of the pled raft is corresponding to the settlement level wherein the stage $\mathrm{AB}$ ends. This settlement can be termed as critical settlement and the load is the limiting capacity. It has also been shown that the equivalent pier theory can be used to evaluate these parameters for the initial stages of design.

\section{REFERENCES}

[1] Clancy P. (1993), Numerical Analysis of Piled Raft Foundations, University of Western Australia, PhD Thesis.

[2] Poulos H.G. (2001), 'Piled Raft Foundation: Design and Application', Geotechnique, Vol. 51, No. 2, pp. 111-113.

[3] Prokoso W.A. and Kulhawy F.H. (2001), 'Contribution of Piled Raft Foundation', Journal of Geotechnical and Geoenvironmental Engineering, ASCE, pp. 17-24.

[4] Balakumar.V (2008), "Experimental Studies of Model Piled Raft on Sand and Field Study of Prototype Behavior". PhD. Thesis, Anna University, Chennai.

[5] Horikoshi K. (1995), 'Optimum Design of Piled Raft Foundations', Dissertation submitted for the degree of Doctor of Philosophy, University of Western Australia.

[6] Polous H.G. (2008), "The Piled Raft Foundation for the Burj Dubai - Design \& Performance". IGS - Ferroco Terzaghi, Oration - 2008.

[7] Yamashita K, Hamada J, Yamada T. (2010), Field Measurements On Piled Rafts with GridForm Deep Mixing Walls on Soft Ground, Geaotechnical Engineering-SEAGS Vol.42 No 2 June 2011

[8] E.Y.N OH, M. Huang, C. Surarak, R. Adamec and A.S. Balasubramaniam (2008), "Finite Element Modeling for Piled Raft Foundation in Sand", Eleventh East Asia - Pacific Conference on Structural Engineering \& Construction (EASEC - 11).

[9] Chin F.K. (1972), 'The Inverse Slope as a Prediction of Ultimate Capacity of Piles', Proc. $3^{\text {rd }}$ S. E. Asian Conf. on Soil Engg, Hongkong, pp. 83-91. 